\title{
In vivo action spectra, absorption and fluorescence excitation spectra of photosensitizers for photodynamic therapy
}

\author{
Willem M. Star \\ Department of Clinical Physics, Dr. Daniel den Hoed Cancer Centre, Rotterdam, Netheriands
}

Received 23 October 1994; accepted 31 October 1994

Keywords: Photodynamic therapy; Action spectrum; Absorption spectrum; Fluorescence excitation spectrum; Haematoporphyrin derivative; Photofrin; Phthalocyanine

Recently the importance of measuring in vivo action spectra for photodynamic therapy (PDT) with various photosensitizers was pointed out in this journal [1]. It was shown that the effect of PDT with zinc phthalocyanine tetrasulphonic acid $\left(\mathrm{ZnPcS}_{4}\right)$ increases considerably when the wavelength of the activating light is increased from 680 to $692 \mathrm{~nm}$. In this regard a further comparison with haematoporphyrin derivative/photofrin and other recently presented information about phthalocyanines may be useful. In particular we wish to point out in this note the possible relevance of the fluorescence excitation spectrum and the possibility to measure the in vivo absorption spectrum of a photosensitizer by reflection spectroscopy.

Preclinical and clinical studies on PDT with haematoporphyrin derivative ( $\mathrm{HpD}$ ) and photofrin have mostly been performed with light of $630 \mathrm{~nm}$ wavelength. The use of this wavelength is not supported by the in vivo action spectrum. The action spectrum for in vitro cell killing by HpD-PDT has a peak close to $630 \mathrm{~nm}$ [2]. However, the in vivo action spectrum for HpD-PDT (determined from damage to rat ears) has peaks close to 500 and $625 \mathrm{~nm} \mathrm{[3].} \mathrm{These} \mathrm{wavelengths} \mathrm{are} \mathrm{the} \mathrm{same}$ as the wavelengths where the fluorescence excitation spectrum has a maximum [4]. Farrell et al. [5] have studied the wavelength dependence of the threshold for PDT-induced damage to rat liver and also found a maximum at $625 \mathrm{~nm}$. Recently Potter et al. [6] (and personal communication) measured the absorption spectrum of photofrin in vivo in a mouse tumor by reflection spectroscopy and observed a maximum at $625 \mathrm{~nm}$. Thus it appears that the in vivo PDT action spectrum, absorption spectrum and fluorescence excitation spectrum using $\mathrm{HpD}$ /photofrin all have a maximum at $625 \mathrm{~nm}$, which differs somewhat from the in vitro PDT action spectrum. The difference between 625 and $630 \mathrm{~nm}$ is not large, but it should be noted that in clinical protocols the wavelength for PDT is often prescribed at $630 \pm 3$ $\mathrm{nm}$. This means that $633 \mathrm{~nm}$ would in principle be acceptable. Since the in vivo HpD-PDT action spectrum has a relatively narrow peak [3], PDT at $633 \mathrm{~nm}$ has considerably less effect than at $625 \mathrm{~nm}$.

Results similar to those of Griffiths et al. [1] for $\mathrm{ZnPCS}_{4}$ have recently been reported for aluminium phthalocyanine disulphonic acid $\left(\mathrm{AlPcS}_{2}\right)$ by Cubeddu et al. [7]. The in vivo absorption spectrum of $\mathrm{AlPcS}_{2}$ peaked at $685 \mathrm{~nm}$ and a similar red shift was found for the PDT action spectrum. Incidentally, Cubeddu et al. [10] also measured the in vivo absorption spectrum of photofrin, which again showed a maximum at 625 $\mathrm{nm}$.

The fluorescence excitation spectrum for $\mathrm{ZnPcS}_{4}$ in cells as reported by Griffiths et al. [1] has a broad maximum that does not correlate well with the PDT action spectrum. In view of the data on $\mathrm{HpD}$ /photofrin it should be worthwhile to measure both the in vivo fluorescence excitation spectrum and the in vivo absorption spectrum of $\mathrm{ZnPcS}_{4}$ to see which, if any, corresponds best with the PDT action spectrum. Another drug requiring such a study is zinc(II)-phthalocyanine in liposomes. This drug will soon be introduced for clinical PDT in a joint effort of Ciba-Geigy and Quadra Logic Technologies. Schieweck et al. [8] reported preclinical studies with this drug. Tumor necrosis required rather high light doses when PDT was performed with $671 \mathrm{~nm}$ light, the wavelength of maximum absorption in $N$-methyl-pyrrolidone. Van Leengoed et al. [9] excited liposomal zinc(II)-phthalocyanine with light of $675 \mathrm{~nm}$ wavelength and also needed rather high light doses $\left(450 \mathrm{~J} \mathrm{~cm}^{-2}\right)$ to achieve tumor necrosis. If liposomal $\mathrm{ZnPc}$ shows the same red shift in the in vivo action spectrum as reported for other phthalo- 
cyanines [1,7], the concomitant reduction in the required light dose for PDT, if performed at the optimum wavelength, has considerable clinical significance. The PDT action spectrum and/or the fluorescence excitation spectrum and the absorption spectrum of liposomal $\mathrm{ZnPc}$ should therefore be studied in vivo before this drug is tested clinically. Naturally this holds for any other new photosensitizer considered for clinical use.

\section{References}

[1] J. Griffiths, J. Cruse-Sawyer, S.R. Wood, J. Schofield, S.B. Brown and $B$. Dixon, On the photodynamic therapy action spectrum of zinc phthalocyanine tetrasulphonic acid in vivo, $J$. Photochem. Photobiol. B: Biol., 24 (1994) 195-199.

[2] C.J. Gomer, D.R. Doiron, N. Rucker, N.J. Razum and S.W. Fountain, Action spectrum $(620-640 \mathrm{~nm})$ for hematoporphyrin derivative induced cell killing, Photochem. Photobiol., 39 (1984) 365-368.

[3] W.M. Star, A.A.C. Versteeg, W.L.J. van Putten and J.P.A. Marijnissen, Wavelength dependence of hematoporphyrin derivative photodynamic treatment effects on rat ears, Photochem. Photobiol., 52 (1990) 547-554.

[4] G.H.M. Gijsbers, D. Breederveld, M.J.C. van Gemert, T.A. Boon, J. Langelaar and R.P.H. Rettschnik, In vivo fluorescence excitation and emission spectra of hematoporphyrin derivative, Lasers Life Sci., 1 (1987) 29-48.
[5] T.J. Farrell, M.C. Olivo, M.S. Patterson, H. Wrona and B.C. Wilson, Investigation of the dependence of tissue necrosis on irradiation wavelength and time post injection using a photodynamic threshold dose model, in P. Spinelli, M. Dal Fante and R. Marchesini (eds.), Photodynamic Therapy and Biomedical Lasers, Elsevier, Amsterdam, 1992, pp. 830-834.

[6] W.R. Potter, D.A. Belinier and A.R. Oseroff, Tissue concentration of sensitizer by in vivo reflectance spectroscopy, Fifth Biann. Meet. Intemational Photodynamic Association, Amelia Island, FL, 21-24 September 1994, Abstract 46.

[7] R. Cubeddu, G. Canti, M. Musolino, A. Pifferi, P. Taroni and G. Valentini, In vivo absorption spectrum of disulphonated aluminium phthalocyanine in tumor bearing mice, Fifth Biann. Meet. Intemational Photodynamic Association, Amelia Island, FL, 21-24 September 1994, Abstract 74.

[8] K. Schieweck, U. Isele, H.-G. Capraro, M. Ochsner, Th. Maurer, J. Kratz, C. Gentsch, G. Jori, A. Segalla and R. Biolo, Preclinical studies with CGP 55847, liposomal zinc(II)-phthalocyanine, Fifth Biann. Meet. International Photodynamic Association, Amelia Island, FL, 21-24 September 1994, Abstract 8.

[9] H.L.L.M. van Leengoed, V. Cuomo, A.A.C. Versteeg, N. van der Veen, G. Jori and W.M. Star, In vivo fluorescence and photodynamic activity of zinc phthalocyanine administered in liposomes, Br. J. Cancer, 69 (1994) 840-845.

[10] R. Cubbedu, G. Canti, M. Musolino, A. Pifferi, P. Taroni and G. Valentini, Absorption spectrum of hematoporphyrin derivative in vivo in a murine tumor model, Photochem. Photobiol., 60 (1994) 582-585. 